\title{
Impact of Droop and Scarf on the Aerodynamic Performance of Compact Aero-Engine Nacelles
}

\author{
Fernando Tejero ${ }^{\mathrm{a}, *}$, David G MacManus ${ }^{\mathrm{a}}$, Christopher Sheaf ${ }^{\mathrm{b}}$ \\ ${ }^{a}$ Centre for Propulsion Engineering, School of Aerospace, Transport and Manufacturing, \\ Cranfield University, Bedfordshire, MK43 OAL \\ ${ }^{b}$ Rolls-Royce plc., P.O. box 31, Derby, United Kingdom, DE24 8BJ
}

\begin{abstract}
Future turbofan engines will operate with larger engine bypass-ratios and lower specific thrust than current in-service architectures to reduce the specific fuel consumption. This will be achieved by increasing the fan diameter which will incur in an increment in nacelle size and a concomitant larger nacelle drag, weight and interaction effects with the airframe. Therefore, it is required to design compact nacelles which will not counteract the benefits obtained from the new engine cycles. Nacelle design is based on a set of aero-lines that in combination with droop and scarf result in a 3D design. Traditionally, this process was performed by the design of axisymmetric aero-lines. Nevertheless, there is an emerging need to carry out the design process for full $3 \mathrm{D}$ configurations to have a better understanding of the effect of droop and scarf angles on the nacelle drag characteristics. This paper presents a numerical method for the multi-objective optimisation of drooped and scarfed non-axisymmetric nacelle aero-engines. It uses intuitive Class Shape Tranformations (iCSTs) for the aero-engine geometry definition, multi-point aerodynamic simulation, a near-field nacelle drag extraction method and the NSGA-II genetic algorithm. The process has been employed to perform independent multi-objective optimisations of compact architectures at selected droop and scarf angle combinations. The multi-objective optimisation framework was successfully demonstrated for the new nacelle de-
\end{abstract}


sign challenge and the overall system was shown to enable the identification of the effects of droop and scarf on compact aero-engines. The proposed tool complements a set of technologies for the design, analysis and optimisation of future civil turbofans aiming at reduction of specific fuel consumption.

\section{Introduction}

The Advisory Council for Aviation Research and Innovation in Europe (ACARE) established very challenging aerospace performance targets for 2050 [1]. It aims to reduce by $80 \%$ the NOx emissions, $75 \%$ the fuel-burn and $65 \%$ the perceived noise with respect to a year-2000 aircraft. In order to meet these objectives future civil aero-engines are expected to have larger bypass ratio (BPR) [2] and lower fan pressure ratio (FPR) [3] than current architectures to reduce the engine specific fuel consumption (SFC) and improve the propulsive efficiency. These new configurations will present larger fan diameters which will have associated an increase on nacelle drag, overall weight and larger interaction effects with the airframe $[4,5]$. Therefore, future civil aero-engines will be mounted in compact nacelles to meet the expected SFC improvements.

One of the main challenges of nacelle design is the requirement for acceptable aerodynamic performance in the broad range of flow conditions that are met throughout the aircraft mission. For future UHBPR nacelle aero-engines and long range applications one key aerodynamic design point is the cruise segment [6]. Traditionally, nacelle design has been tackled by multi-point aerodynamic optimisation in which mid-cruise conditions, sensitivity to flight Mach number and sensitivity to massflow capture ratio (MFCR) are considered. Tejero et al.

\footnotetext{
* Corresponding author.

E-mail address: f.tejero@cranfield.ac.uk
}

Preprint submitted to AIAA SciTech Forum 2020

$05 / 01 / 2020$ 
[6] developed a nacelle optimisation framework for axisymmetric configurations based on a CFD in-the-loop approach for compact aero-engines in which the sensitivity to the nacelle design parameters of $L_{n a c} / r_{h i}$ and $r_{t e} / r_{h i}$ was quantified. The method was successfully demonstrated for the identification of the viable nacelle design space for future civil aero-engines. Robinson et al. [7] carried out a multi-point optimisation for two UHBPR turbofan nacelles with a conventional length of $L_{n a c} / r_{h i}=4.3$ and a compact architecture with $L_{n a c} / r_{h i}=$ 3.1. A maximum reduction of $16.1 \%$ in mid-cruise nacelle drag was achieved on the compact configuration with respect to the long nacelle aero-engine. Albert et al. [8] investigated different parametric geometry definitions for the design of axisymmetric nacelles aero-engines. It was concluded that the Class Shape Transformation (CST) outperformed the super-ellipses and B-spline methods.

Although the basic form of nacelle design is based on a set of axisymmetric aero-lines which in combination with droop and scarf result in a 3D design, it is still required to have a better insight of the transonic flow aerodynamics associated to non-axisymmetric configurations. This also includes a better understanding of the impact of droop and scarf on the nacelle drag characteristics for the new nacelle design challenge of UHBPR aero-engines. These angles define the offset required for the highlight plane to re-orient the intake axis. The majority of previous non-axisymmetric nacelle design studies are based on multi-fidelity methods that include RANS simulations, surrogate modelling and genetic algorithms $[9,10,11]$. These investigations do not quantify the impact of the droop and scarf angles on the aerodynamic performance as they were fixed during the design process. Fang et al. [9] carried out the optimisation of a non-axisymmetric configuration with $L_{n a c} / r_{h i}=3.5$ using Class Shape Transformations and 20 design variables to describe the aero-engine. The study was focus on a medium range application at $\mathrm{M}=0.80$ in which the main objective 
was to minimise the nacelle drag. The proposed method yielded to a configuration with a reduction of $1.5 \mathrm{dc}$ with respect to a reference configuration. Peters et al. [11] investigated the effects of short intakes on nacelle drag at cruise conditions for a medium range application $(\mathrm{M}=0.80)$. It was concluded that the nacelle external drag could be reduced by $15 \%$ by employing short-inlet configurations of $L_{\text {int }} / D_{\text {fan }}=0.19$ with respect to $L_{\text {int }} / D_{\text {fan }}=0.5$. On the other hand, other studies have quantified the impact of droop and scarf on intake performance metrics $[12,13,14]$. The investigations were mainly focused on negative drooped and scarfed configurations. The benefits of these architectures have been demonstrated for take-off conditions to delay the incidence angle at which the intake flow separates [12] as well as for the reduction of the perceived noise at ground level [14]. Nevertheless, these studies do not evaluate the nacelle drag under cruise conditions which is vital for long range applications.

\subsection{Scope of the present work}

This work further develops a computational method for the multi-point multi-objective optimisation of non-axisymmetric nacelle configurations. The tool encompasses an analytical formulation for the parametric definition of the aero-engine with intuitive Class Shape Transformations, multi-point aerodynamic simulations, a near-field nacelle drag extraction method and the NSGA-II genetic algorithm.

The aim of this work is to demonstrate the capabilities of the developed framework for the new nacelle design challenge. The tool is employed for the optimisation of 3D non-axisymmetric configurations for different ranges of droop and scarf angles to assess the trade-off of these two design variables on the nacelle drag characteristics. The method is subsequently employed to derive guidelines for the design of compact nacelles. 


\section{Nacelle design framework}

This work is based on the framework for the aerodynamic design of nacelle aero-engines developed by Tejero et al. $[6,15]$. The method has a set of modules that include a parametric representation of the aero-engine with intuitive Class Shape Transformations (iCST) [16], automatic structured mesh generation [17], computation of the viscous compressible flow-field [18], post-processing to extract the pertinent objective functions [19] as well as a multi-objective optimisation capability with genetic algorithms [20]. A detailed description of each module is presented below.

\subsection{Geometry definition and mesh generation}

The developed tool uses a geometry parameterisation of the nacelle aerolines based on intuitive Class Shape Transformations (iCST) [16, 21]. This formulation provides sufficient geometric control and is also tractable within an optimisation and design requirement. The parameterisation has been tested for axisymmetric nacelle design applications with success [6] and has been extended to construct 3D nacelles which can accommodate azimuthal aero-line variations as well as the necessary intake droop and scarf requirements (Figure 1). The current fancowl definition employes 7 intuitive design variables to describe a single aero-line: $r_{h i}, r_{t e}, L_{n a c}, f_{\max }, r_{\max }, f_{i f}, \beta_{\text {nac }}$ (Figure 1a). The method has been extended to non-axisymmetric configurations by employing eight control lines, which are reduced to five as left-right symmetry is considered in this work (Figure 1b). For each design variable CST curves are created in the cylindrical coordinate system and the values at intermediate aero-lines are calculated by interrogating the associated CST curves. Therefore, for fixed end-points $\left(L_{n a c} / r_{h i}\right.$ and $\left.r_{t e} / r_{h i}\right)$ the current non-axisymmetric nacelle definition is based on 5 control aero-lines $\left(\psi=0^{\circ}, 45^{\circ}, 90^{\circ}, 135^{\circ}\right.$ and $\left.180^{\circ}\right)$ which are described by 4 nacelle design variables each. Overall, the method uses 20 nacelle variables 


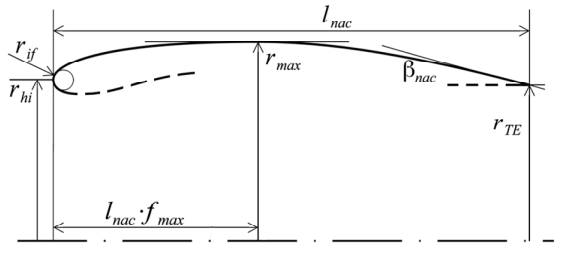

(a) Single aero-line nacelle design variables

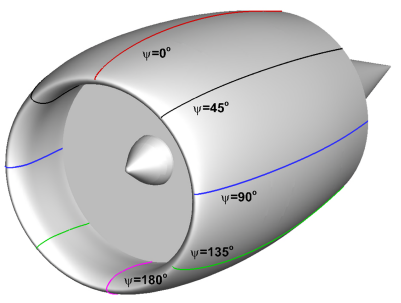

(b) 3D nacelle with marked controlled aero-lines

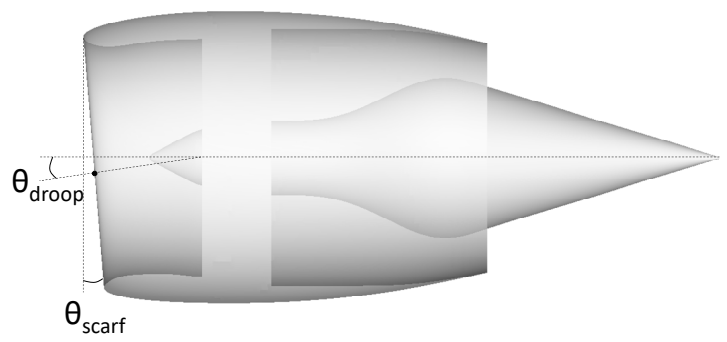

(c) Definition of the droop and scarf angles

Figure 1: 2D axi-symmetric and 3D non-axisymmetric nacelle definition

and the droop and scarf angles to describe a non-axisymmetric nacelle aeroengine configuration (Figure 1c). The tool uses a generic intake and exhaust system to minimise the interactions with the nacelle drag characteristics. A conical exhaust is employed to generate a representative post-exit streamtube to extract the post-exit force term (Figure 1c).

The framework has an automated meshing capability with a multi-block structured computational domain [17] (Figure 2). The radial discretisation of the boundary layer block around the viscous walls employes $y^{+} \approx 30$.

\subsection{Computational method}

The compressible Favre-averaged Navier-Stokes equations are solved with a double precision density-based solver and an implicit time integration formulation [18]. A second-order upwind scheme for the spatial discretisation with a Green-Gauss node based scheme and the 2-equations $k-\omega$ Shear-Stress Trans- 
port (SST) turbulence model are employed [22]. The Sutherland's law [23] is used to calculate the dynamic viscosity. The convergence criteria for each numerical simulation throughout the optimisation routine is based on a reduction of five order of magnitude on the normalised residuals and changes lower than $0.05 \%$ over the last 300 iterations on the fan massflow and the fancowl force.

The boundary conditions are imposed to fulfill the user prescribed flight conditions of Mach number, MFCR, altitude and incidence angle. The spinner, intake and fan cowl are set with a no-slip and adiabatic wall condition. The inlet fan face uses a pressure-outlet boundary conditions in which a target massflow value is set according to the prescribed MFCR. The fan exit is defined by a pressure-inlet conditions of total pressure and temperature. The freestream conditions are set with the the flight Mach number, angle of attack and the associated static temperature and pressure of the desired user-prescibed altitude (Figure 2b).

Subsequently the framework automatically extracts the nacelle drag by employing the industrial thrust-drag bookkeeping approach from AGARD [19]. The nacelle drag is composed by the contribution of the pressure and viscous forces on the fan cowl $\left(\phi_{n a c}\right)$, the pre-entry force $\left(\phi_{\text {pre }}\right)$ and the post-exit force $\left(\phi_{\text {post }}\right)$. Whilst the contribution of $\phi_{n a c}+\phi_{\text {pre }}$ is calculated with a modified nearfield method [24], the post-exit force is obtained by the numerical integration of the pressure term along the streamlines from the nacelle trailing edge.

\subsubsection{Grid convergence study and numerical validation}

The influence of the domain size on the nacelle drag was assessed by locating the farfield boundary conditions at four different location with respect to the nacelle maximum radius: $60 r_{\max }, 80 r_{\max }, 100 r_{\max }$ and $120 r_{\max }$. The study reveled that the nacelle drag increased only by $0.05 \%$ between the $100 r_{\max }$ and $120 r_{\max }$ cases and the $100 r_{\max }$ domain size was selected within this investiga- 


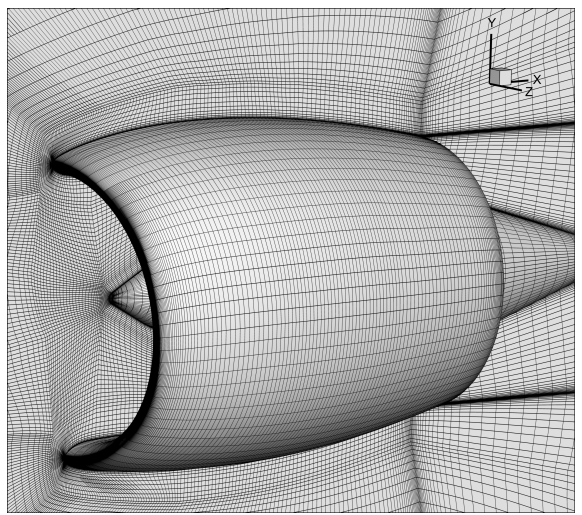

(a) Mesh detail on the nacelle surface and symmetry plane

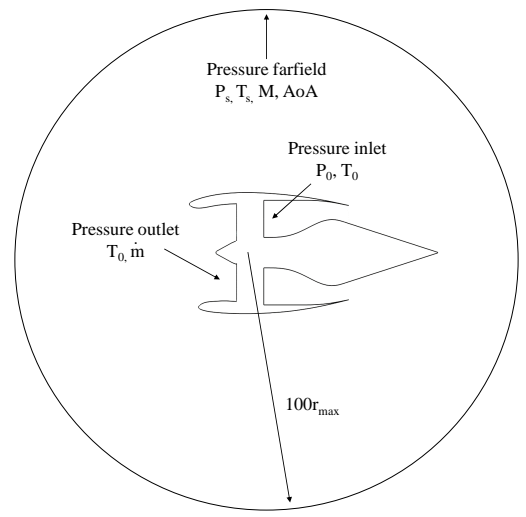

(b) Computational domain and boundary conditions

Figure 2: Computational domain and 3D view of the mesh used on the developed tool

tion (Figure 2b). A mesh independence study was calculated for four different mesh sizes (200k. 400k, 800k and 1600k) and the grid convergence index (GCI) was evaluated for the different levels of refinement considered. The $800 \mathrm{k}$ mesh size presented a value of $\mathrm{GCI}=0.5 \%$ on mid-cruise nacelle drag and was selected within the optimisation routine.

The numerical method was previously validated for a range of flight conditions across Mach numbers from 0.80 and 0.89 and MFCR from 0.45 and 0.70 [25]. The computational nacelle drag coefficient was underpredicted by approximately $3.0 \%$ at mid-cruise type conditions with $\mathrm{M}=0.85$ and $\mathrm{MFCR}=0.70$. The predicted drag rise Mach number was within 0.002 with respect the the measurements [25].

\subsection{Optimisation routine}

The developed nacelle optimisation tool encompasses the capability of Design Space Exploration (DSE) studies as well as an optimisation environment. The design of experiments is started with a Latin Hypercube Sampling (LHS) due to the proven capabilities to efficiently cover high-dimensional design spaces [26]. The optimisation can be performed with three different strategies: (a) higher 
fidelity CFD in-the-loop approach, (b) lower fidelity approach from a response surface model obtained with the DSE results and (c) an adaptive method that combines numerical simulations and the construction of RSMs [15]. The tool has a multi-point multi-objective design optimisation capability based on the Non-dominated Sorted Genetic Algorithm II (NSGA-II) genetic algorithm [20].

For this investigation the framework has been employed with the full CFD in-the-loop approach. The multi-point multi-objective optimisation is carried out for three different flight conditions that are encountered within the cruise segment: mid-cruise drag (Eq. 1), sensitivity to flight Mach number (Eq. 2) and sensitivity to changes on massflow capture ratio (Eq. 3).

$$
\begin{gathered}
C_{D-\text { cruise }}=\frac{D_{\text {nac }}}{\frac{1}{2} \rho_{\infty} V_{r e f}^{2} A_{h i}} \\
\Delta C_{D-M a c h}=\frac{D_{\text {nac }, M=M_{r e f}+0.02-D_{n a c, M=M_{r e f}}}}{\frac{1}{2} \rho_{\infty} V_{r e f}^{2} A_{h i}} \\
C_{D-\text { spill }}=\frac{D_{\text {nac }, M F C R_{\text {cruise }}-D_{\text {nac }, M F C R_{E O C}}}}{\frac{1}{2} \rho_{\infty} V_{r e f}^{2} A_{h i}}
\end{gathered}
$$

\section{Results and discussions}

A compact nacelle architecture of expected future civil aero-engines with $L_{n a c} / r_{h i}=3.1$ and $r_{t e} / r_{h i}=0.91$ has been considered. The multi-objecive optimisations were carried out for representative flight conditions of long-range applications with mid-cruise conditions of $\mathrm{M}=0.85, \mathrm{MFCR}=0.70$ and $\mathrm{h}=$ $10668 \mathrm{~m}$. The flight Mach number was increased to $\mathrm{M}=0.87$ at the same massflow capture ratio and altitude to quantify the sensitivity to Mach number. To account for the reduction of ingested massflow across the flight profile, the MFCR was set to 0.65 at the same $M=0.85$ and $h=10668 \mathrm{~m}$ of the mid-cruise 
conditions.

\subsection{Demonstration of the tool for $3 D$ nacelle optimisation}

The developed numerical method has been employed for the multi-objective optimisation of a compact nacelle aero-engine in which the variables $f_{\max }, r_{\max }$, $r_{i f}$ and $\beta_{n a c}$ of the 5 controlled aero-lines float during the optimisation routine. Therefore, a total of 20 nacelle design variables are considered which highlights the relatively large aerodynamic design space. The capabilities of the framework for non-axisymmetric nacelle design is demonstrated for a configuration in which $\theta_{\text {droop }}$ is aligned with the freestream incidence angle $(\mathrm{AoA})$ and $\theta_{\text {scarf }} / \theta_{\text {droop }}=$ 1.3 .

The optimisation process starts with a Latin Hypercube Sampling [26] design of experiments. Overall, 400 designs were evaluated by CFD during the design space exploration. The following generations of the evolutionary algorithm are also evaluated with numerical simulations. The multi-objective optimisation is continued until the Pareto optimal set of solution has a hypervolume variation lower than $1.0 \%$ in the last three generations.

The optimisation routine resulted in a 3D Pareto front which is presented with a projection into the $C_{D-\text { cruise }}-\Delta C_{D-\text { Mach }}$ space and coloured by $C_{D-\text { spill }}$ (Figure 3a). It demonstrates the non-linearity of compact nacelle aero-engines. Whilst there are nacelle designs with low spillage nacelle drag $\left(C_{D-\text { spill }}\right)$ but a large concomitant sensitivity to Mach number $\left(\Delta C_{D-M a c h}\right)$ and mid-cruise conditions $\left(C_{D-\text { cruise }}\right)$, the optimal solutions for $\Delta C_{D-\text { Mach }}$ have associated large penalties on $C_{D-\text { spill }}$ and $C_{D-c r u i s e}$. This is highlighted on the nacelle designs $\mathrm{C} 1, \mathrm{C} 2$ and $\mathrm{C} 3$ which are the configurations with the lowest $C_{D-\text { cruise }}$, $\Delta C_{D-M a c h}$ and $C_{D-\text { spill }}$, respectively. Relative to $\mathrm{C} 1$, the $\mathrm{C} 2$ configuration reduces $\Delta C_{D-M a c h}$ by 0.0029 at the expense of an increment by $8.7 \%$ on midcruise nacelle drag and a larger sensitivity to changes on MFCR with an incre- 


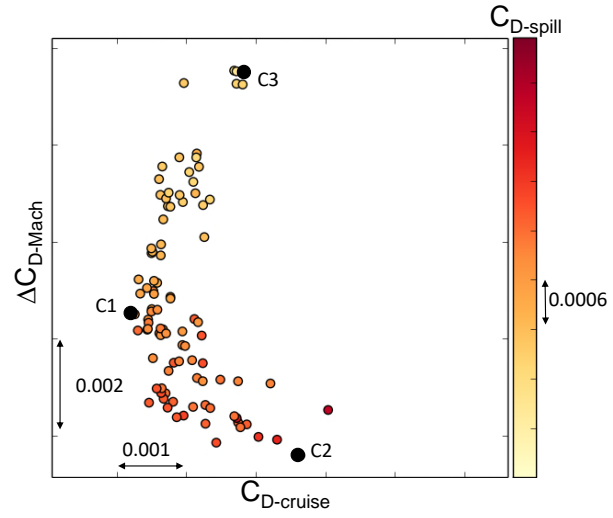

(a) Pareto optimal set of solutions

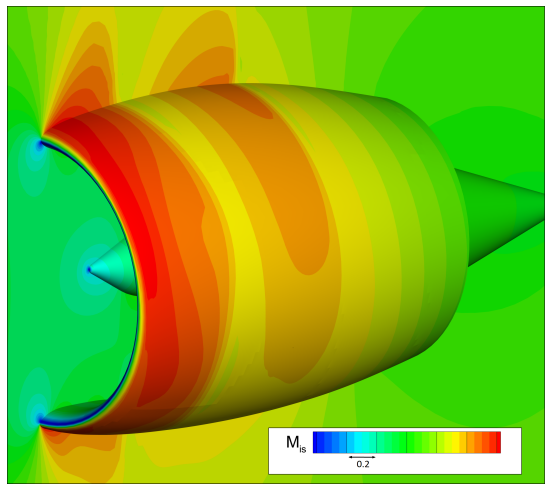

(c) $\mathrm{C} 2$ nacelle design

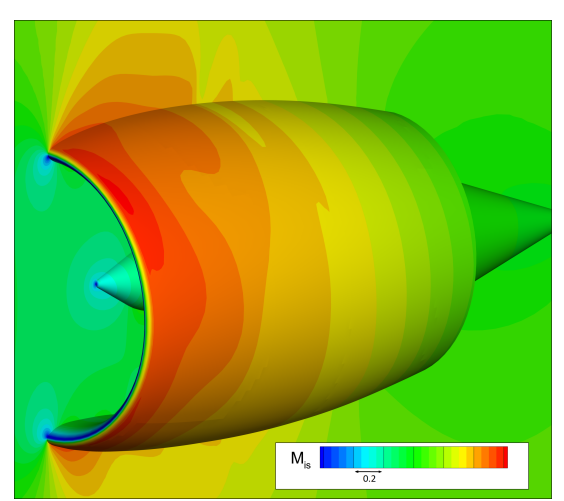

(b) $\mathrm{C} 1$ nacelle design

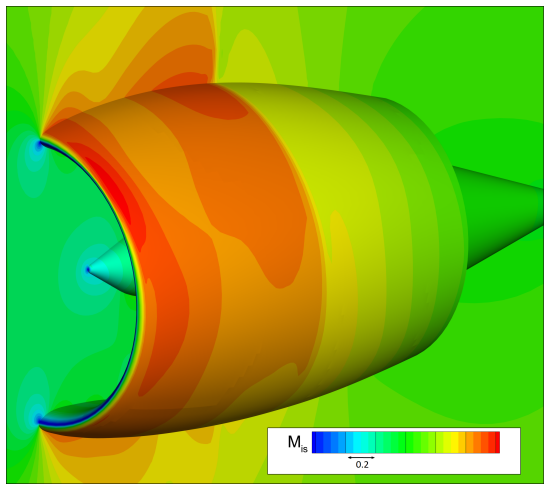

(d) C3 nacelle design

Figure 3: Pareto front and isentropic Mach number distribution of the selected designs with $L_{n a c} / r_{h i}=3.1$ and $r_{t e} / r_{h i}=0.91, \theta_{\text {droop }}=$ AoA, $\theta_{\text {scarf }}=1.3 \theta_{\text {droop }}$

ment of 0.0016 on $C_{D-\text { spill }}$. The $\mathrm{C} 3$ nacelle has the lowest spillage drag but a concomitant increment on mid-cruise drag by $5.3 \%$ and a larger sensitivity to changes on flight Mach number with respect to $\mathrm{C} 1$.

The large variation on the nacelle drag characteristics is caused by a fundamental change on the associated nacelle transonic flow aerodynamics (Figure 3 ). The peak isentropic Mach number at the top aero-line $\left(\psi=0^{\circ}\right)$ is significantly different on the three selected designs and varies by 0.11 (Figure 3 ). The configuration $\mathrm{C} 1$, which has the lowest $C_{D-\text { cruise }}$ found throughout the optimisation process, has a well defined shock-wave at $X / L_{n a c}=0.40$ on the top aero-line 
(Figure 4a). The design $\mathrm{C} 2$ has a double shock structure with a first shock located at $X / L_{n a c}=0.18$ a second shock-wave at $X / L_{n a c}=0.53$. Relative to the pre-shock $M_{i s}$ of $\mathrm{C} 1$, the strength of the pre-shock $M_{i s}$ for the design $\mathrm{C} 2$ increases by 0.04 and 0.03 in the first and second shock-wave, respectively. Conversely, $\mathrm{C} 3$ has an initial deceleration after the peak $M_{i s}$ and then the flow accelerates to terminate with a strong shock-wave at $X / L_{n a c}=0.47$ (Figure 4a). For the azimuthal section $\psi=45^{\circ}$ all three designs have similar peak $M_{i s}$ (Figure $4 \mathrm{~b}$ ). Then, differences in the flow structures start to arise between the configurations. While the $\mathrm{C} 1$ design has a monotonic reduction of $M_{i s}$ along the aero-line and $\mathrm{C} 2$ depicts a double shock-wave pattern, the $\mathrm{C} 3$ configuration has a single strong shock structure. Although similar flow structures appear on the side aero-line $\left(\psi=90^{\circ}\right)$ with respect to the $\psi=45^{\circ}$ aero-line (Figure $4 \mathrm{c}$ ), there is a noticeable change on the intensity of the associated transonic flow aerodynamics. For example, the $\mathrm{C} 3$ design has a peak $M_{i s}$ reduction of 0.09 between $\psi=45^{\circ}$ and $90^{\circ}$. Both aero-lines have a well defined shock at $X / L_{n a c}=0.49$ but a difference on the pre-shock $M_{i s}$ of 0.05 . Lastly, the controlled aero-lines at $\psi=135^{\circ}$ and $180^{\circ}$ present relatively benign transonic flow aerodynamics. For instance, the double shock topology of the $\mathrm{C} 2$ configuration at $\psi=0^{\circ}, 45^{\circ}$ and $90^{\circ}$ (Figures $4 \mathrm{a}, 4 \mathrm{~b}$ and $4 \mathrm{c}$ ) is not present at the bottom aero-line (Figure $4 \mathrm{~d}$ ), in which there is single shock structure. The described results highlight the larger flow acceleration around the nacelle lip and the stronger shock-wave at the control lines $\psi=0^{\circ}$ and $45^{\circ}$ with respect to $\psi=90^{\circ}, 135^{\circ}$ and $180^{\circ}$, which shows the impact that both aero-lines may have on the nacelle drag.

The developed nacelle design framework has been demonstrated for the new nacelle design challenge. The tool has been successfully employed to evaluate drooped and scarfed non-axisymmetric configurations within the context of midcruise conditions and sensitivity to changes on flight Mach number and MFCR. 


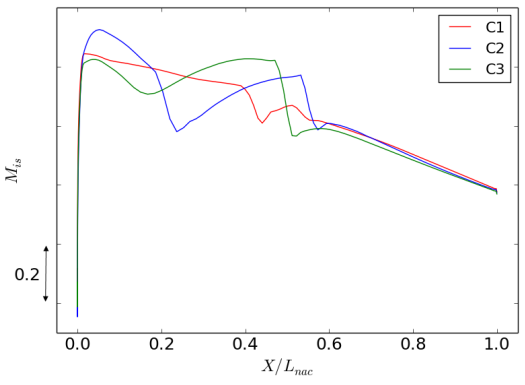

(a) $\psi=0^{\circ}$

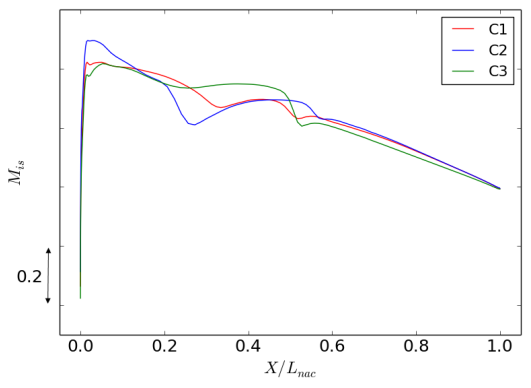

(c) $\psi=90^{\circ}$

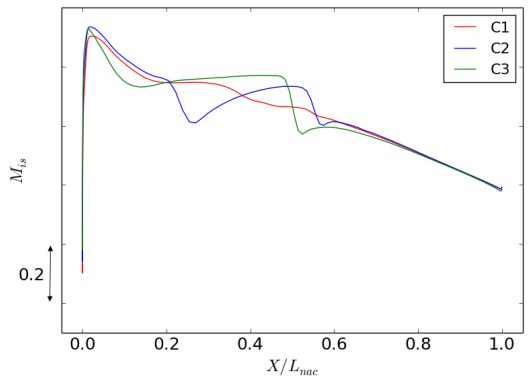

(b) $\psi=45^{\circ}$

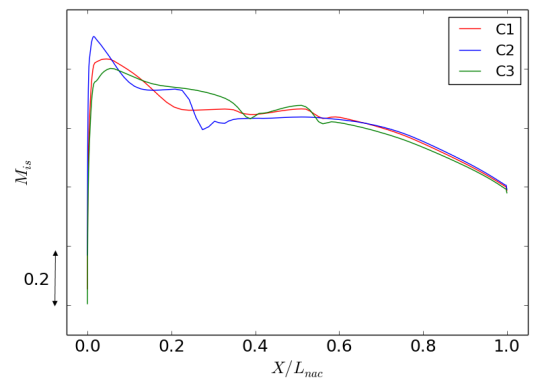

(d) $\psi=180^{\circ}$

Figure 4: Comparison of $M_{i s}$ for selected designs at different azimuthal sections 


\begin{tabular}{|c|c|c|}
\hline Configuration & $\theta_{\text {droop }}$ & $\theta_{\text {scarf }} / \theta_{\text {droop }}$ \\
\hline A & AoA $-2.0^{\circ}$ & 1.3 \\
\hline B & AoA $-1.0^{\circ}$ & 1.3 \\
\hline C & AoA & 1.3 \\
\hline D & AoA $+1^{\circ}$ & 1.3 \\
\hline
\end{tabular}

Table 1: Summary of cases in which the effects of droop and scarf angles have been studied

As such, the proposed method constitutes an useful tool for the design of future nacelle civil aero-engines and provides the confidence to conduct extensive numerical simulations to assess the impact of the droop and scarf angles on the nacelle drag characteristics.

\subsection{Aerodynamic impact of droop and scarf}

A set of independent MOOs were carried out for a range of different $\theta_{\text {scarf }}$ and $\theta_{\text {droop }}$ angles (Table 1). For each configuration the MOO was performed with the established method of an initial DOE with 400 design evaluations and subsequent generations also evaluated with CFD until reaching convergence to the Pareto front based on the hypervolume value. The configuration $\mathrm{C}$ in Table 1 refers to the previously described multi-objective optimisation.

The independent MOOs resulted in 3D optimal sets of solutions upon which the impact of droop and scarf in the nacelle aerodynamic performance can be quantified. The comparison between the different configurations is performed for the nacelle design with minimum drag that has a potential acceptable spillage with $C_{D-\text { spill }}<0.1 C_{D-\text { cruise }}[6]$. Across the range of cases considered the mid-cruise drag vary by $3.5 \%$ (Figure 5 ). Relative to the design selected from configuration $\mathrm{C}$ (named $\mathrm{C} 1$ in the previous section), a reduction of $\theta_{\text {droop }}$ and $\theta_{\text {scarf }}$ by $-1.0^{\circ}$ and $-1.3^{\circ}$ results in an optimal design for the configuration $\mathrm{B}$ with a $1.4 \%$ penalty on mid-cruise drag. As the droop and scarf angles was reduced by $-2.0^{\circ}$ and $-2.6^{\circ}$ on the case $\mathrm{A}$, the optimisation process resulted in a nacelle 


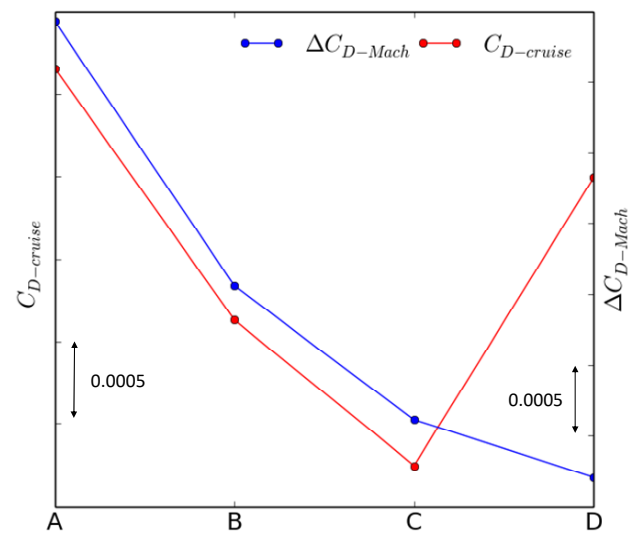

Figure 5: Changes on mid-cruise drag $\left(C_{D}\right.$-cruise $)$ and sensitivity to Mach number $\left(\Delta C_{D-M a c h}\right)$ for selected designs identified from the independent multi-objective optimisation routines

configuration with a $C_{D-\text { cruise }}$ increment of $3.5 \%$ with respect to the design C. The optimisation of the configuration $\mathrm{D}$ resulted on a design with a penalty on mid-cruise drag of $2.5 \%$. It is a larger penalty than the one for configuration $\mathrm{B}$ at the same variation on the droop and scarf angles but different polarity. This is caused by the larger sensitivity to changes on MFCR $\left(C_{D-\text { spill }}\right)$ of the configuration $\mathrm{D}$ which results on the selection of a design with a larger cruise drag to meet the established selection criteria of $C_{D-\text { spill }}<0.1 C_{D-\text { cruise }}[6]$. The compact nacelles have lower sensitivity to changes on flight Mach number $\left(\Delta C_{D-M a c h}\right)$ as the values of droop and scarf angles are increased (Figure 5).

The selected nacelle designs have significant differences on their transonic flow aerodynamics (Figure 6). The designs with the reduced droop and scarf angles, e.g. A and B, have larger peak $M_{i s}$ on the top half $\left(0^{\circ}<\psi<90^{\circ}\right)$ than the designs with increased droop and scarf values, e.g. design D. This is caused by the reduction of the nacelle aero-line length as the scarf angle reduces, which decreases the curvature of the local aero-lines and increases the acceleration along the nacelle lip. Conversely, on the nacelle bottom half $\left(90^{\circ}<\psi<180^{\circ}\right)$ 
the designs $\mathrm{A}$ and $\mathrm{B}$ have a more benign acceleration along the nacelle lip than the design $\mathrm{D}$ due to the larger effective nacelle length. Figure 7 compares the changes on $M_{i s}$ for the selected designs at the azimuthal sections $\psi=0^{\circ}$ and $180^{\circ}$. At the top nacelle aero-line, the maximum value of isentropic Mach number along the nacelle forebody varies by 0.09 for the selected configurations (Figure 7a). All four optimal designs have a well defined shock-wave structure. The shock-wave is located on the nacelle crest at $X / L_{n a c} \approx 0.40$ with similar preshock $M_{i s}$ for the configurations $\mathrm{A}, \mathrm{B}$ and $\mathrm{C}$. The nacelle $\mathrm{D}$ has a deceleration after the nacelle lip and then the flow accelerates again to terminate in a normal shock at $X / L_{n a c}=0.49$. The selected designs have noticeable changes on the peak $M_{i s}$ at the bottom aero-line $\left(\psi=180^{\circ}\right)$ (Figure $7 \mathrm{~b}$ ). Relative to the design A, which has the largest effective nacelle length on the bottom aero-line, the peak $M_{i s}$ increases by $0.06,0.12$ and 0.16 for the designs $\mathrm{B}, \mathrm{C}$ and $\mathrm{D}$, respectively. While the nacelles $\mathrm{A}, \mathrm{B}$ and $\mathrm{C}$ have relatively benign flow aerodynamics after the peak $M_{i s}$, the design D depicts a shock structure after the nacelle crest at $X / L_{n a c}=0.53$.

\section{Conclusion}

A novel framework for the multi-objective optimisation of non-axisymmetric nacelle aero-engines has been further developed. It encompasses a parametric aero-engine definition with intuitive Class Shape Transformations, numerical simulations, a thrust-drag bookkeeping accounting method and a evolutionary algorithm. The tool has been used to investigate the impact of the droop and scarf angles on the nacelle drag characteristics of compact configurations. The optimisation process was carried out with a higher fidelity CFD in-the-loop approach to evaluate the nacelle drag throughout the design process.

A set of independent multi-objective optimizations for different droop and 


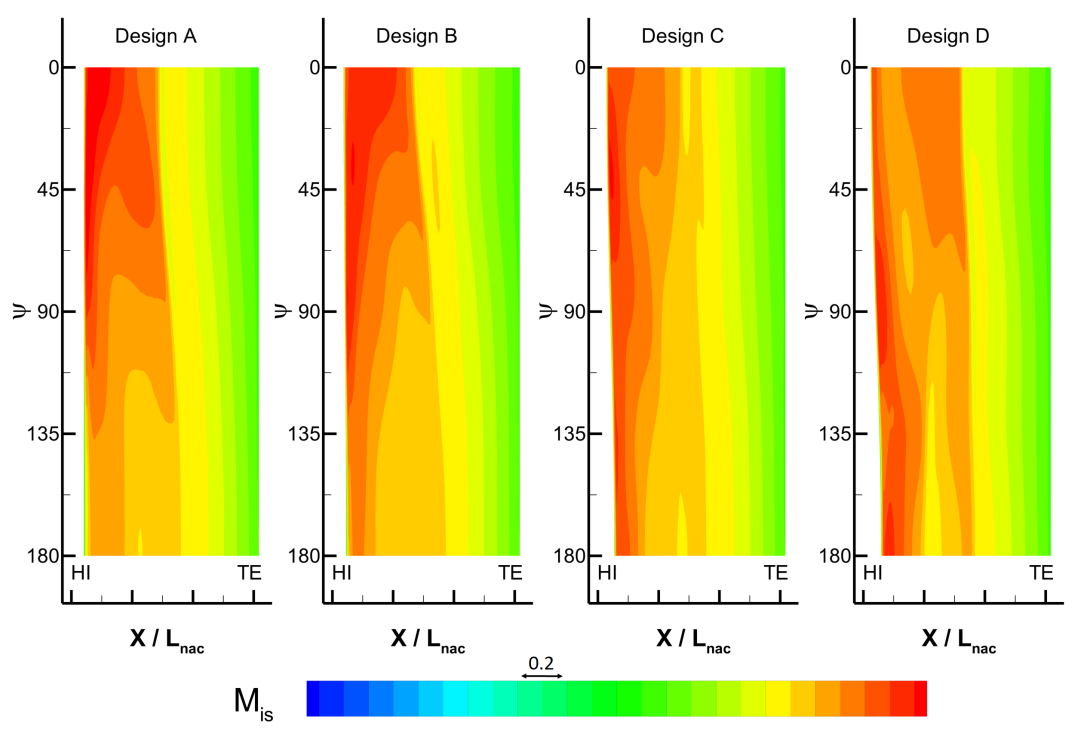

Figure 6: Isentropic Mach number distribution for selected designs identified from the independent multi-objective optimisation routines

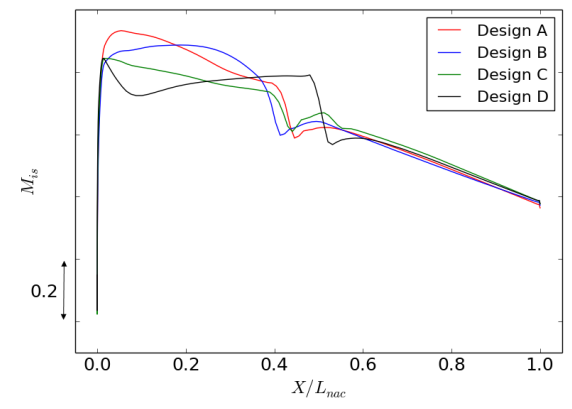

(a) $\psi=0^{\circ}$

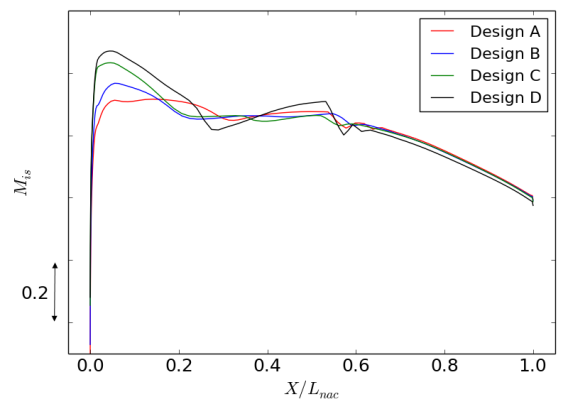

(b) $\psi=180^{\circ}$

Figure 7: Comparison of $M_{i s}$ at different azimuthal sections for selected designs identified from the independent multi-objective optimisation routines 
scarf angles were carried out. Across the ranges considered the nacelle midcruise drag varies by $3.5 \%$. The presented results demonstrate the relatively large impact of both design variables on the nacelle drag characteristics. As such, they need to be adequately selected to maximise the expected benefits of future civil aero-engine architectures. The tool has been successfully employed to identity the changes on the transonic flow aerodynamics of the different configurations investigated. The proposed numerical method complements a set of enabling technologies for the design, analysis and optimisation of future civil large turbofans aiming at reduction of specific fuel consumption.

\section{References}

[1] European Commission, Flightpath 2050: Europe's Vision for Aviation, Tech. Rep. ISBN 978-92-79-19724-6, Publications Office of the European Union (2011).

[2] N. Birch, 2020 Vision: The Prospects for Large Civil Aircraft Propulsion, The Aeronautical Journal 104 (1038) (2000) 347-352.

[3] A. Guha, Optimum Fan Pressure Ratio for Bypass Engines with Separate or Mixed Exhaust Streams, Journal of Propulsion and Power 17 (5) (2011) $1117-1122$.

[4] D. Daggett, Ultra-Efficient Engine Technology Systems Integration and Environmental Assessment, Tech. Rep. CR-2002-211754, NASA (2002).

[5] F. Tejero, I. Goulos, D. MacManus, C. Sheaf, Effects of Aircraft Integration on Compact Nacelle Aerodynamics, in: AIAA SciTech Forum and Exposition, 2020. 
[6] F. Tejero, M. Robinson, D. MacManus, C. Sheaf, Multi-Objective Optimization of Short Nacelles for High Bypass Ratio Engines, Aerospace Science and Technology 91 (2019) 410-421.

[7] M. Robinson, D. MacManus, K. Richards, C. Sheaf, Short and Slim Nacelle Design for Ultra-High BPR Engines, in: 55th AIAA Aerospace Sciences Meeting, AiAA SciTech Forum, AIAA Paper Number 2017-0707, 2017.

[8] M. Albert, D. Bestle, Aerodynamic Design Optimization of Nacelle and Intake, in: Proceedings of ASME Turbo Expo 2013: Turbine Technical Conference and Exposition, no. GT2013-94857, American Society of Mechanical Engineers, 2013.

[9] X. Fang, Y. Zhang, S. Li, , H. Chen, Transonic Nacelle Aerodynamic Optimization Based on Hybrid Genetic Algorithm, in: 17th AIAA/ISSMO Multidisciplinary Analysis and Optimization Conference, AIAA AVIATION Forum, AIAA Paper Number 2016-3833, 2016.

[10] Y. Zhong, S. Li, A 3D Shape Design and Optimization Method for Natural Laminar Flow Nacelle, in: Proceedings of ASME Turbo Expo 2017: Turbomachinery Technical Conference and Exposition, Paper Number GT201764379, Vol. 1, 2017, pp. 825-830.

[11] A. Peters, Z. S. Spakovszky, W. K. Lord, B. Rose, Ultrashort Nacelles for LowFan Pressure Ratio Propulsors, Journal of Turbomachinery 110 (2015) $265-288$.

[12] J. M. Abbot, Aerodynamic Performance of Scarf Inlets, in: 17th Aerospace Sciences Meeting, AIAA Paper 79-0380, 1979.

[13] T. S. Crum, D. E. Yates, T. L. Andrew, N. O. Stockman, Low Speed Test 
Results of Subsonic, Turbofan Scarf Inlets, in: AIAA/SAE/ASME/ASEE 29th Joint Propulsion Conference and Exhibit, AIAA 93-2301, 1993.

[14] R. Nangia, M. Palmer, Negatively Scarfed Inlets for Acoustic Reduction, Aerodynamic Performance Assessment, in: 38th Aerospace Sciences Meeting and Exhibit, AIAA Paper 2000-0354, 2000.

[15] F. Tejero, D. MacManus, C. Sheaf, Surrogate-Based Aerodynamic Optimisation of Compact Nacelle Aero-Engines, Aerospace Science and Technology 93 (105207).

[16] R. Christie, A. Heidebrecht, D. G. MacManus, An Automated Approach to Nacelle Parameterisation Using Intuitive Class Shape Transformation Curves, Journal of Engineering for Gas Turbines and Power 139 (1153).

[17] Ansys Inc., 275 Technology Drive, Canonsburg, PA 15317, ANSYS ICEM CFD Tutorial Manual.

[18] Ansys Inc., 275 Technology Drive, Canonsburg, PA 15317, ANSYS FLUENT User's Guide.

[19] M.-I. D. A. P. M. S. Group, Guide to In-Flight Thrust Measurement of Turbojets and Fan Engines, Tech. Rep. AG-237, AGARDograph No. 237, Report AGARD (1979).

[20] K. Deb, A. Pratap, S. Agarwal, T. Meyarivan, A Fast and Elitist Multiobjective Genetic Algorithm: NSGA-II, IEEE Transactions on Evolutionary Computation 6, (2) (2002) $182-197$.

[21] R. Christie, M. Robinson, F. Tejero, D. MacManus, The Use of Hybrid Intuitive Class Shape Transformation Curves in Aerodynamic Design, Aerospace Science and Technology, doi: 10.1016/j.ast.2019.105473doi:10.1016/j.ast.2019.105473. 
[22] F. R. Menter, Two-Equation Eddy-Viscosity Turbulence Models for Engineering Applications, AIAA Journal 32 (8) (1994) 1598-1605.

[23] W. Sutherland, The Viscosity of Gases and Molecular Force, Philosophical Magazine Series 536 (1893) 507-531.

[24] R. Christie, S. Ramirez, D. MacManus, Aero-Engine Installation Modelling and the Impact on Overall Flight Performance, in: Advanced Aero Concepts, Design and Operations Conference, 2014.

[25] M. Robinson, D. MacManus, C. Sheaf, Aspects of Aero-Engine Nacelle Drag, Proceedings of the Institution of Mechanical Engineers, Part G: Journal of Aerospace Engineering 233 (5).

[26] J. C. Helton, F. J. Davis, Latin Hypercube Sampling and the Propagation of Uncertainty in Analyses of Complex Systems, Engineering and System Safety 81 (2003) 23-69. 
2020-01-05

Impact of droop and scarf on the aerodynamic performance of compact aero-engine nacelles

Tejero, Fernando

AIAA

Tejero F, MacManus DG \& Sheaf C (2020) Impact of droop and scarf on the aerodynamic performance of compact aero-engine nacelles. In: Proceedings of the 2020 AIAA Scitech Forum, 6-10 January, Orlando, Florida, USA

https://doi.org/10.2514/6.2020-1522

Downloaded from Cranfield Library Services E-Repository 